\title{
Lionello Sozzi, Un inquieto sorriso. Lettura di cinque favole di La Fontaine
}

\section{Laura Rescia}

\section{Q OpenEdition}

1 Journals

\section{Edizione digitale}

URL: http://journals.openedition.org/studifrancesi/9522

DOI: 10.4000/studifrancesi.9522

ISSN: 2421-5856

Editore

Rosenberg \& Sellier

\section{Edizione cartacea}

Data di pubblicazione: 1 décembre 2007

Paginazione: 652-653

ISSN: 0039-2944

\section{Notizia bibliografica digitale}

Laura Rescia, «Lionello Sozzi, Un inquieto sorriso. Lettura di cinque favole di La Fontaine», Studi Francesi [Online], 153 (LI | III) | 2007, online dal 30 novembre 2015, consultato il 09 janvier 2021. URL: http:// journals.openedition.org/studifrancesi/9522 ; DOI: https://doi.org/10.4000/studifrancesi.9522

Questo documento è stato generato automaticamente il 9 janvier 2021.

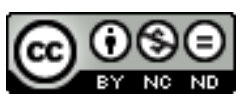

Studi Francesi è distribuita con Licenza Creative Commons Attribuzione - Non commerciale - Non opere derivate 4.0 Internazionale. 


\title{
Lionello Sozzi, Un inquieto sorriso. Lettura di cinque favole di La Fontaine
}

\author{
Laura Rescia
}

\section{NOTIZIA}

LIONELlo sozzI, Un inquieto sorriso. Lettura di cinque favole di La Fontaine, Pisa, Pacini

Editore, 2004, pp. 148.

1 Leggerezza e profondità, gaieté e malinconia, illusione e realtà: sono solo alcuni degli ossimori attraverso i quali L. Sozzi invita a riscoprire La Fontaine, regalando ai suoi lettori un testo critico che rispecchia molte caratteristiche del suo oggetto.

Individuando alcune tra le tematiche fondative delle Fables (la questione etico-politica, il rapporto tra sogno e realtà, il ruolo del sapere) e dipanandone la poetica, tutta connotata da una ritrosia che si concretizza nella brevitas dell'ellissi e nella litote, L. Sozzi giunge a identificare la cifra fondamentale dell'opera del favolista: l'ambiguità del messaggio etico-morale, spesso assai più complesso di quanto la sua apparente facilità indurrebbe a credere. Dopo la ricca introduzione, corredata da un utile profilo biografico, da cenni sulla fortuna dell'autore e da una sceltissima bibliografia, si aprono i capitoli dedicati alle cinque favole annunciate dal titolo. Titolo davvero ingannevole e riduttivo, poiché la lettura rivela una ricchezza e una complessità di rinvii testuali e intratestuali che permettono di scoprire in filigrana una fittissima rete di modelli letterari, nonché la tessitura tematica interna alle favole. Così nel primo saggio, dedicato a Les animaux malades de la peste (VII, 1), si individuano le fonti a cui La Fontaine ha attinto: gli exempla, il filone riformato, la matrice umanistica e quella orientale. Ognuna viene vagliata e soppesata, vengono riconosciuti i prestiti ideologici, di motivi o più semplicemente di singoli spunti. Grazie al percorso critico di Sozzi si evince come il favolista riesca a ricostruire un tessuto narrativo il cui valore è assai più alto della semplice somma delle parti. Non nell'invenzione dei tasselli del mosaico risiede infatti la grandezza di La Fontaine, ma nella capacità di subordinare ogni 
dettaglio narrativo e stilistico al messaggio, in questo caso la condanna dell'ipocrisia. $\mathrm{E}$ se l'ironia è innegabile, è svelando la tragicità dei toni, dovuta alla consapevolezza dei mali del mondo, che Sozzi rivela l'onnipresente duplicità e inquietudine di La Fontaine. Anche il terzo studio, dedicato a Le paysan du Danube (XI,7), si articola sulla lettura delle fonti, che consente di ravvisare nella riscrittura del favolista una sicura intenzione etica contro l'ingordigia dell'individuo, ancora lontana da spunti primitivistici e tantomeno ispirata a ideologie antimperialiste, sebbene rimanga più di un dubbio sulla sua volontà di accennare alle mire espansionistiche di Colbert. Il secondo studio di Sozzi si muove invece trasversalmente alle favole che riguardano il rapporto tra realtà e illusione, e attraverso questo approccio critico la favola La lattière et le pot au lait (VII, 9) si chiarisce con una nuova rivelazione di ambiguità: l'aspirazione al sogno e alla chimera non sono appiattiti dalla condanna della moralità, ma sempre considerati con condiscendenza, con tenerezza, e ancor più, riconoscendo al sogno un ruolo indispensabile alla vita dell'uomo.

Il tema del potere e del suo utilizzo ritorna ne Les compagnons d'Ulysse (XII, 1), testo a cui è dedicato il quarto studio. Qui Sozzi dimostra come La Fontaine si distacchi tanto dalle fonti classiche (Plutarco) che da quelle umanistiche (Machiavelli e Gelli), che veicolavano entrambe la tensione verso il sacro, per additare invece la superiorità della ragione, capace di tenere a bada le passioni. A questo primo messaggio, rivolto al giovane duca di Borgogna, Sozzi vede affiancato un ulteriore invito: quello a perseguire la concordia e la pace, anziché la guerra e la violenza, destinato al Dauphin, padre del giovane destinatario esplicito del testo. Il libro si chiude sul quinto studio, che meglio di altri illustra come ogni nuova interpretazione non possa che poggiare su una precisa ed erudita documentazione: Sozzi ricostruisce gli ascendenti di due favole (V,8 e XII,17) apparentate da una serie di funzioni e motivi, che erano state finora commentate talora con affastellamenti di riferimenti testuali, talaltra con riduttive semplificazioni, giungendo a ricostruire la catena delle dipendenze in ogni suo anello. La loro genesi è ripercorsa con limpidità, e per la seconda vengono ipotizzate nuove fonti.

Questi studi riprendono e sistematizzano i contenuti di memorabili lezioni di Lionello Sozzi, tenute in affollate aule dell'Ateneo torinese: per quelle e per questo libro non possiamo che sentirci suoi debitori. 